ARTICLE

DOI: $10.1038 / \mathrm{s} 41467-018-02819-7$

\title{
Active sites of copper-complex catalytic materials for electrochemical carbon dioxide reduction
}

\author{
Zhe Weng 10 1,2,3, Yueshen Wu 2,3, Maoyu Wang ${ }^{4}$, Jianbing Jiang ${ }^{2,3}$, Ke Yang 2,3 , Shengjuan Huo 2,3,5, \\ Xiao-Feng Wang6, Qing Ma7, Gary W. Brudvig ${ }^{2,3}$, Victor S. Batista ${ }^{2,3}$, Yongye Liang ${ }^{1}$, \\ Zhenxing Feng ${ }^{4} \&$ Hailiang Wang (1) 2,3
}

Restructuring-induced catalytic activity is an intriguing phenomenon of fundamental importance to rational design of high-performance catalyst materials. We study three coppercomplex materials for electrocatalytic carbon dioxide reduction. Among them, the copper(II) phthalocyanine exhibits by far the highest activity for yielding methane with a Faradaic efficiency of $66 \%$ and a partial current density of $13 \mathrm{~mA} \mathrm{~cm}^{-2}$ at the potential of $-1.06 \mathrm{~V}$ versus the reversible hydrogen electrode. Utilizing in-situ and operando $\mathrm{X}$-ray absorption spectroscopy, we find that under the working conditions copper(II) phthalocyanine undergoes reversible structural and oxidation state changes to form $\sim 2 \mathrm{~nm}$ metallic copper clusters, which catalyzes the carbon dioxide-to-methane conversion. Density functional calculations rationalize the restructuring behavior and attribute the reversibility to the strong divalent metal ion-ligand coordination in the copper(II) phthalocyanine molecular structure and the small size of the generated copper clusters under the reaction conditions.

\footnotetext{
${ }^{1}$ Department of Materials Science and Engineering, South University of Science and Technology of China, Shenzhen 518055, China. ${ }^{2}$ Department of Chemistry, Yale University, New Haven, CT 06511, USA. ${ }^{3}$ Energy Sciences Institute, Yale University, West Haven, CT 06516, USA. ${ }^{4}$ School of Chemical, Biological, and Environmental Engineering, Oregon State University, Corvallis, OR 97331, USA. ${ }^{5}$ Department of Chemistry, Science Colleges, Shanghai University, Shanghai 200444, China. ${ }^{6}$ School of Chemistry and Chemical Engineering, University of South China, Hengyang, Hunan 421001, China. ${ }^{7}$ DNDCAT, Synchrotron Research Center, Northwestern University, Evanston, IL 60208, USA. Zhe Weng, Yueshen Wu and Maoyu Wang contributed equally to this work. Correspondence and requests for materials should be addressed to Y.L. (email: liangyy@sustc.edu.cn) or to Z.F. (email: zhenxing.feng@oregonstate.edu) or to H.W. (email: hailiang.wang@yale.edu)
} 
E lectrochemical conversion of $\mathrm{CO}_{2}$ using electricity generated from renewable energy sources could provide viable solutions to the development of carbon-neutral fuels. However, $\mathrm{CO}_{2}$ electroreduction is a kinetically slow and diverging reaction that requires a significant magnitude of overpotential and generates a myriad of products ${ }^{1-3}$. Among all the electrocatalyst materials studied thus far for $\mathrm{CO}_{2}$ reduction metal complexes are of distinct importance, because they possess welldefined structures that can be tailored on the molecular level ${ }^{4-10}$. Therefore, there is a significant interest in the development of electrocatalytic materials by deposition of molecules with high catalytic activity and selectivity for electrochemical $\mathrm{CO}_{2}$ reduction $^{6,11-14}$. Cu-based metal organic frameworks (MOFs) have been found to be electrocatalytically active for reducing $\mathrm{CO}_{2}$ to alcohols ${ }^{14}$. Recently, we discovered a $\mathrm{Cu}$ porphyrin based heterogeneous electrocatalyst that can reduce $\mathrm{CO}_{2}$ to methane $\left(\mathrm{CH}_{4}\right)$ and ethylene $\left(\mathrm{C}_{2} \mathrm{H}_{4}\right)$ in a neutral aqueous electrolyte ${ }^{15}$. Although postmortem analysis reveals that the $\mathrm{Cu}$ porphyrin molecular structure remains unchanged after electrolysis, the actual active species responsible for catalyzing $\mathrm{CO}_{2}$ to hydrocarbon conversion has yet to be established.

Many catalyst materials change their structures under reaction conditions $^{16-18}$. The restructuring can be induced by physical conditions such as temperature, pressure, and electrical potential, as well as chemical conditions such as adsorbates and reactants ${ }^{17-}$ 25 . The formed structures with reduced thermodynamic energy under the reaction conditions are responsible for the observed catalytic properties. Metal surfaces are known to alter their atomic arrangements, compositions, and oxidation states under the influences of gas atmosphere and temperature ${ }^{21}$. Numerous studies have been reported on molecular complexes of earthabundant metals as pre-catalysts for water oxidation ${ }^{26}$. Recently, transition metal sulfides, selenides, and phosphides have been found to reconstruct themselves to the corresponding oxides or (oxy)hydroxides and effectively catalyze electrochemical oxygen evolution $^{27,28}$. Examining the restructuring of catalyst materials is crucial to understanding structure-reactivity correlations and to designing better catalysts.

In situ and operando characterization techniques are highly useful in uncovering catalyst restructuring phenomena, as they can provide chemical and physical information under reaction conditions ${ }^{29-33}$. Under certain circumstances where the reconstructed catalysts are subject to further structural changes when the reaction conditions are removed, operando characterization is necessary to identify the real catalytically active species. In this regard, in-situ and operando X-ray absorption spectroscopy (XAS) is particularly powerful, as the X-ray absorption near edge structure (XANES) can reveal the oxidation state of the element of interest, and extended X-ray absorption fine structure (EXAFS) is capable of probing the influence from the local coordination environment. For example, sub-monolayer $\mathrm{VO}_{x}$ anchored on an $\alpha-\mathrm{Fe}_{2} \mathrm{O}_{3}$ powder surface undergoes redox-induced dynamic changes of atomic structure and oxidation state, as revealed stepby-step with in-situ $\mathrm{XAS}^{34}$. In another study, XAS is used to determine the cation occupation of the octahedral and tetrahedral sites in spinel oxides ${ }^{35}$, which is then identified as a property descriptor of the catalytic activity of these materials for the oxygen reduction and evolution reactions ${ }^{36}$.

Here we report the restructuring of three molecularly structured $\mathrm{Cu}$ catalysts under electrochemical $\mathrm{CO}_{2}$ reduction conditions as probed by in-situ and operando XAS, and the correlation of the catalyst structures to the observed catalytic properties. The three $\mathrm{Cu}$-complex materials, namely copper(II) phthalocyanine (CuPc), copper(II) benzene-1,3,5-tricarboxylate (btc) MOF (HKUST-1), and copper(II) 1,4,8,11-tetraazacyclotetradecane chloride $\left([\mathrm{Cu}(\right.$ cyclam $\left.)] \mathrm{Cl}_{2}\right)$, all show catalytic activity toward $\mathrm{CO}_{2}$ reduction to $\mathrm{CH}_{4}$, working as heterogeneous catalysts in $0.5 \mathrm{M}$ $\mathrm{KHCO}_{3}$ aqueous electrolyte. Among them, the $\mathrm{CuPc}$ catalyst exhibits the highest activity and selectivity; the partial current density and Faradaic efficiency of the $\mathrm{CH}_{4}$ product reach $13 \mathrm{~mA}$ $\mathrm{cm}^{-2}$ and $66 \%$ at $-1.06 \mathrm{~V}$ vs the reversible hydrogen electrode (RHE), respectively. Thus, $\mathrm{CuPc}$ represents one of the most efficient catalysts for electrochemical reduction of $\mathrm{CO}_{2}$ to $\mathrm{CH}_{4}$. In situ and operando XANES and EXAFS studies reveal that the $\mathrm{CuPc}$ molecules restructure to metallic $\mathrm{Cu}$ clusters with a size of $\sim 2 \mathrm{~nm}$ under the working conditions and the $\mathrm{Cu}$ nanoclusters convert back to the original $\mathrm{CuPc}$ structure upon release of the negative electrode potential. In contrast, HKUST-1 and $[\mathrm{Cu}($ cyclam $)] \mathrm{Cl}_{2}$ irreversibly decompose to form much larger $\mathrm{Cu}$ nanostructures. These comparisons indicate that the good performance of the $\mathrm{CuPc}$ catalyst originates from the reversible formation of $\mathrm{Cu}$ nanoclusters. Further analysis provides deeper understanding toward designing metal-complex molecular structures for controllably generating active species under reaction conditions to catalyze desirable chemistry.

\section{Results}

Electrocatalytic measurements. $\mathrm{CuPc}$ is a molecular complex with the $\mathrm{Cu}^{2+}$ ion coordinated by the conjugated planar $\mathrm{Pc}^{2-}$ ligand (Fig. 1a). HKUST-1 is a MOF with $\mathrm{Cu}$ (II) nodes coordinated by negatively charged btc linkers (Fig. 1b). $\left[\mathrm{Cu}(\right.$ cyclam) $] \mathrm{Cl}_{2}$ features a $\mathrm{Cu}^{2+}$ ion coordinated by a non-conjugated chargeneutral ligand (Fig. 1c). The three materials were each mixed with mildly oxidized multi-wall carbon nanotubes $(\mathrm{CNTs})^{20,37,38}$ to form a catalyst layer on electrodes for electrocatalytic measurements in $\mathrm{CO}_{2}$-saturated $0.5 \mathrm{M} \mathrm{KHCO}_{3}$ aqueous solution. Controlled-potential electrolysis was performed with the working electrode potential being varied in the range between -0.76 and $-1.36 \mathrm{~V}$ vs RHE at $0.1 \mathrm{~V}$ intervals. At relatively lower overpotentials, the major $\mathrm{CO}_{2}$ reduction products over the $\mathrm{CuPc}$ catalyst are formic acid $(\mathrm{HCOOH}), \mathrm{C}_{2} \mathrm{H}_{4}$, and $\mathrm{CO}$ (Fig. 1d), with the Faradaic efficiencies being 25, 13, and $6 \%$ at $-0.86 \mathrm{~V}$, respectively. As the electrode potential goes to $-0.96 \mathrm{~V}, \mathrm{CH}_{4}$ becomes the dominant $\mathrm{CO}_{2}$ reduction product. At $-1.06 \mathrm{~V}$, a maximum Faradaic efficiency of $66 \%$ together with a partial current density of $13 \mathrm{~mA} \mathrm{~cm}^{-2}$ is achieved for $\mathrm{CO}_{2}$ conversion to $\mathrm{CH}_{4}$ (Fig. 1d, e), corresponding to a $\mathrm{CH}_{4}$ formation rate of 0.36 $\mathrm{mmol} \mathrm{s}^{-1} \mathrm{~g}_{\mathrm{CuPc}}{ }^{-1}$ and $0.86 \mu \mathrm{mol} \mathrm{C}^{-1}$. The HKUST-1 and $[\mathrm{Cu}($ cyclam $)] \mathrm{Cl}_{2}$ catalysts are also active for catalyzing $\mathrm{CO}_{2}$ electroreduction to $\mathrm{CH}_{4}$. However, the onset potentials are $100 \sim 200 \mathrm{mV}$ more negative than that of the CuPc catalyst. HKUST-1 reaches a maximum Faradaic efficiency of $27 \%$ at $-1.16 \mathrm{~V}$ with a partial current density of $4.4 \mathrm{~mA} \mathrm{~cm}^{-2}$ (Supplementary Fig. 1), whereas $[\mathrm{Cu}($ cyclam $)] \mathrm{Cl}_{2}$ electrodes does so at $-1.26 \mathrm{~V}$ with the Faradaic efficiency and partial current density being $15 \%$ and $2.8 \mathrm{~mA} \mathrm{~cm}^{-2}$ (Supplementary Fig. 2). The Faradaic efficiencies and partial current densities of the gas-phase products over the three catalyst electrodes at $-1.06 \mathrm{~V}$ are compared in Fig. 1f, g. It can be clearly discerned that $\mathrm{CuPc}$ is a much more active and selective electrocatalyst than HKUST-1 and $[\mathrm{Cu}($ cyclam $)] \mathrm{Cl}_{2}$ for $\mathrm{CO}_{2}$ reduction to $\mathrm{CH}_{4}$.

In situ and operando XANES measurements. To probe the structural and oxidation state changes of these Cu-complex electrocatalysts as they perform $\mathrm{CO}_{2}$ reduction, we carried out insitu XAS measurements (Supplementary Fig. 3) under the same electrochemical conditions. During the measurements, the working electrode potential was first deceased in steps from the open circuit voltage $(\mathrm{OCV}, \sim 0.8 \mathrm{~V}$ vs $\mathrm{RHE})$ to $-1.06 \mathrm{~V}$ vs $\mathrm{RHE}$, and then increased back to $0.64 \mathrm{~V}$. Each potential was held for at least $1 \mathrm{~h}$ until the XAS spectra were recorded. Thus, the results 


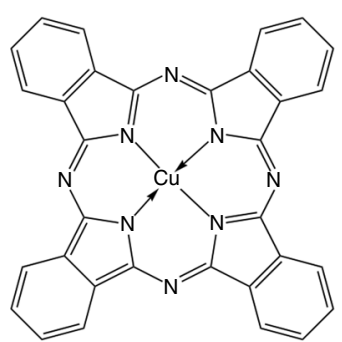

b

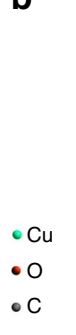

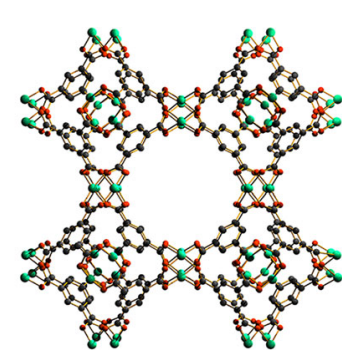

C
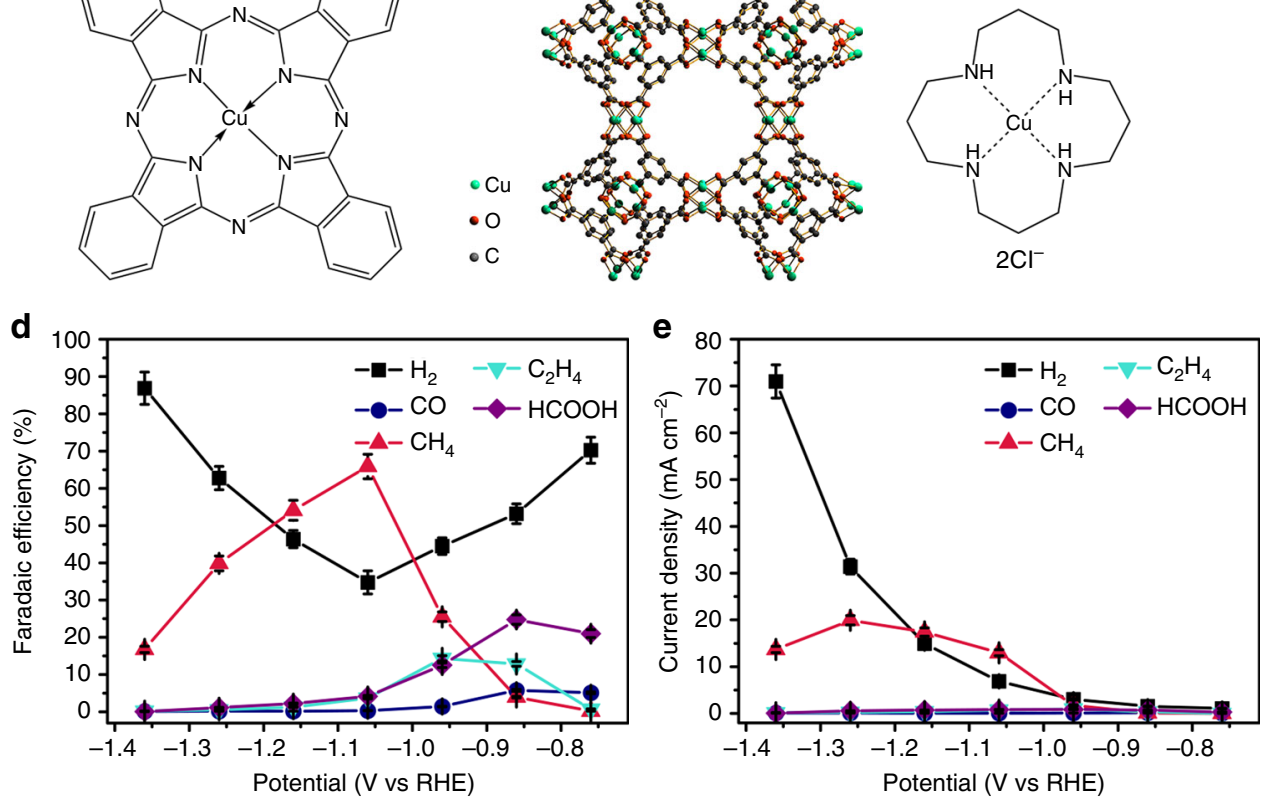

$\mathbf{f}$

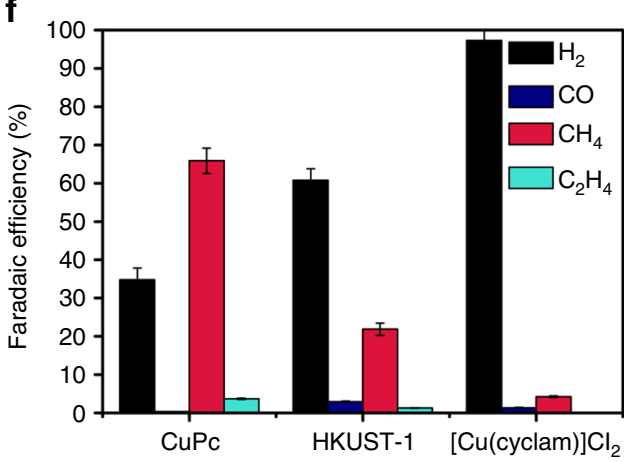

g

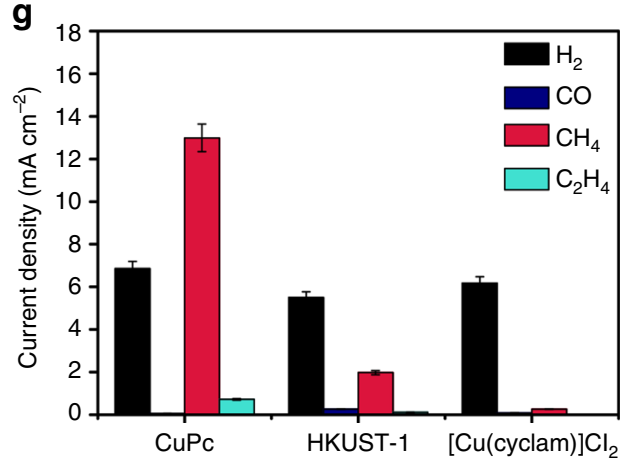

Fig. 1 Molecular structures of three Cu-complex materials and their electrocatalytic performance for $\mathrm{CO}_{2}$ reduction. Molecular structures of a CuPc, b HKUST-1, and $\mathbf{c}[\mathrm{Cu}(\mathrm{cyclam})] \mathrm{Cl}_{2}$. Potential-dependent $\mathbf{d}$ Faradaic efficiencies and e partial current densities of products for $\mathrm{CO}_{2}$ electroreduction reaction catalyzed by $\mathrm{CuPc}$. Comparison of $\mathbf{f}$ Faradaic efficiency and $\mathbf{g}$ partial current density distributions among $\mathrm{CO}_{2}$ electroreduction reactions catalyzed by the three materials at $-1.06 \mathrm{~V}$ vs RHE. Error bars represent the SD from multiple measurements

reflect stable states under the electrochemical conditions. Under the initial OCV conditions, all the three catalysts show a characteristic $\mathrm{Cu}(\mathrm{II})$ peak $(1 \mathrm{~s} \rightarrow 3 \mathrm{~d}$ transition) at $\sim 8,985 \mathrm{eV}$ in the corresponding normalized $\mathrm{Cu}$ K-edge XANES spectrum (Fig. 2a, $\mathrm{d}, \mathrm{g})$. As the potential applied to the CuPc electrode is decreased to $-0.66 \mathrm{~V}$, a small absorption peak appears at $\sim 8,981 \mathrm{eV}$ in the spectrum (Fig. 2a), indicating the formation of $\mathrm{Cu}(\mathrm{I})$. Another peak at $\sim 8,980 \mathrm{eV}$ starts to develop at $-0.86 \mathrm{~V}$, which corresponds to $\mathrm{Cu}(0)$. At $-1.06 \mathrm{~V}$, where the highest Faradaic efficiency for $\mathrm{CO}_{2}$ reduction to $\mathrm{CH}_{4}$ is reached, the XANES is dominated by the $\mathrm{Cu}(0)$ feature. The spectral evolution and absorption peaks can be discerned more clearly in the derivative curves of the XANES spectra (Fig. 2b). It is worth noting that the $\mathrm{Cu}(\mathrm{II})$ peak persists throughout all the applied potentials (Fig. 2a, b), which means that not all the $\mathrm{Cu}(\mathrm{II})$ centers are converted to lower oxidation states under the $\mathrm{CO}_{2}$ reduction conditions. Upon switching the electrode potential back to $0.64 \mathrm{~V}$, the $\mathrm{Cu}(0)$ peak disappears and the XANES spectrum is almost restored to that under the initial OCV conditions (Fig. 2a, b), suggesting that the potential-induced oxidation state changes for the CuPc catalyst are reversible. In contrast, neither the HKUST-1 nor the $[\mathrm{Cu}$ (cyclam) $] \mathrm{Cl}_{2}$ exhibits such a reversibility, though both of them are converted to $\mathrm{Cu}(0)$ at $-1.06 \mathrm{~V}$ (Fig. $2 \mathrm{~d}, \mathrm{e}, \mathrm{g}, \mathrm{sh}$ ). The cycled
HKUST-1 electrode mainly contains $\mathrm{Cu}(\mathrm{I})$ species while the $[\mathrm{Cu}$ (cyclam) $] \mathrm{Cl}_{2}$ electrode is dominated by metallic $\mathrm{Cu}$ (Fig. $2 \mathrm{~d}, \mathrm{e}, \mathrm{g}, \mathrm{h}$ and Supplementary Fig. 4).

In situ and operando EXAFS measurements. To examine the local coordination environment changes, we performed in-situ EXAFS measurements. At the working potential of $-1.06 \mathrm{~V}$, all the three catalysts exhibit a characteristic metallic $\mathrm{Cu}-\mathrm{Cu}$ bond peak at $R=\sim 2.2 \AA$ in the corresponding Fourier-transformed EXAFS spectrum (Fig. 2c, f, i), which is consistent with the appearance of $\mathrm{Cu}(0)$ observed in the XANES spectra. In particular, the EXAFS spectra of HKUST- 1 and $[\mathrm{Cu}(\mathrm{cyclam})] \mathrm{Cl}_{2}$ at $-1.06 \mathrm{~V}$ are similar to that of the $\mathrm{Cu}$ metal standard in the entire $R$ and $k$ ranges (Fig. 2f, i and Supplementary Figs 4, 5), suggesting formation of bulk $\mathrm{Cu}$ metal. As the electrode potential returns to $0.64 \mathrm{~V}$, the metallic $\mathrm{Cu}$ originated from HKUST-1 is oxidized to $\mathrm{Cu}_{2} \mathrm{O}$, which is supported by the similarity to the EXAFS spectrum of the $\mathrm{Cu}_{2} \mathrm{O}$ standard (Fig. $2 \mathrm{f}$ and Supplementary Fig. 5). $\mathrm{The} \mathrm{Cu}(0)$ species derived from $[\mathrm{Cu}(\mathrm{cyclam})] \mathrm{Cl}_{2}$ form a reddish metallic sheen on the electrode (Supplementary Fig. 6), which results in reduced and noisy signals in the XAS spectrum recorded at $-1.06 \mathrm{~V}$ (Supplementary Fig. 4). In contrast, the $\mathrm{CuPc}$ 
a

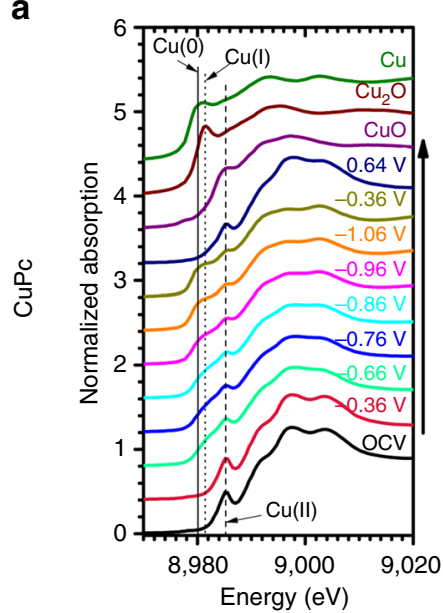

d

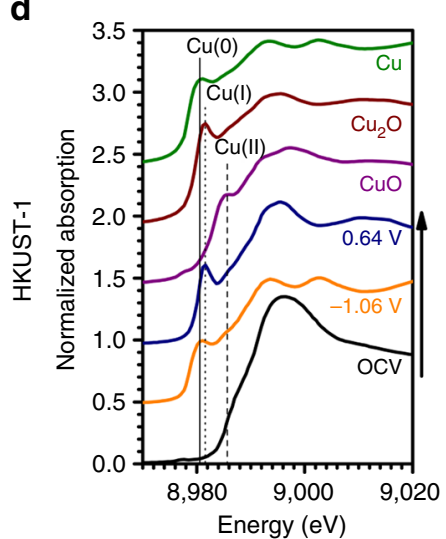

g

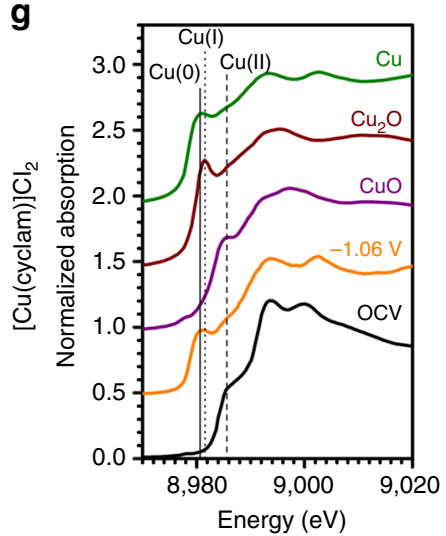

b

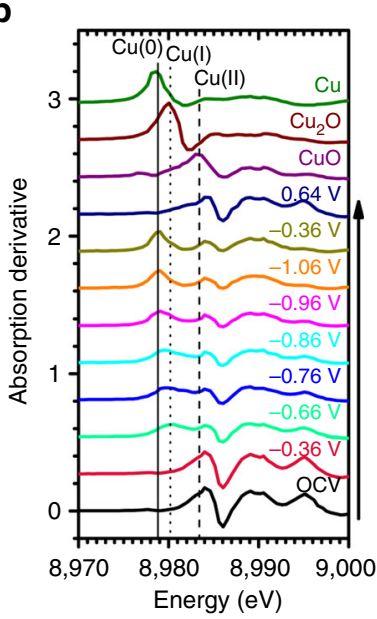

e

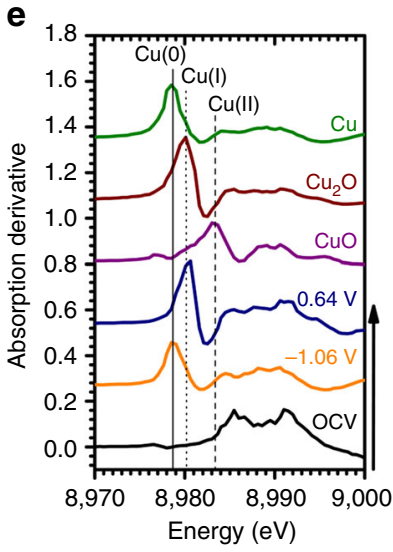

h

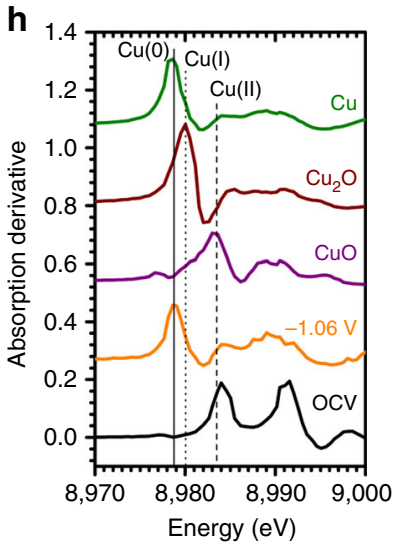

c

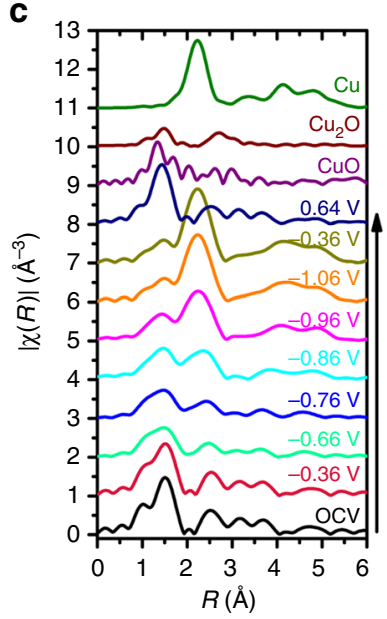

f

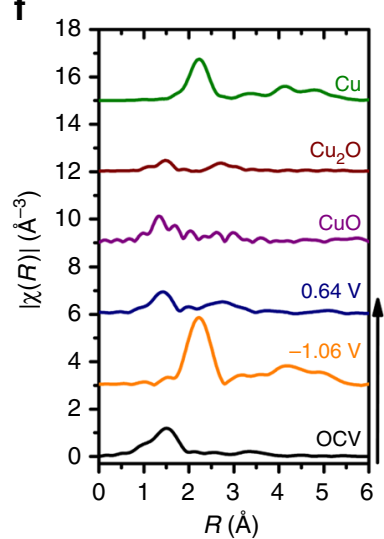

i

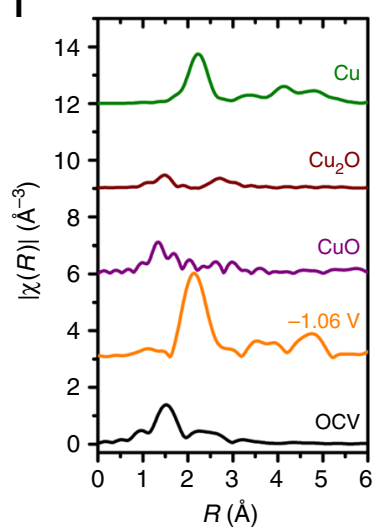

Fig. 2 In situ XAS measurements under electrocatalytic reaction conditions. a Cu K-edge XANES spectra, $\mathbf{b}$ first-order derivatives of the XANES spectra, and $\mathbf{c}$ Fourier-transformed Cu K-edge EXAFS spectra for CuPc. Similarly, the corresponding XAS spectra for HKUST-1 are plotted in $\mathbf{d}-\mathbf{f}$ and for [Cu (cyclam) $\mathrm{Cl}_{2}$ in $\mathbf{g}$-i. The slight off-alignment of the $\mathrm{Cu}(\mathrm{II})$ peaks in the XANES derivatives $\mathbf{b}, \mathbf{e}, \mathbf{h}$ with that of $\mathrm{CuO}$ is mainly due to the different local geometries of the $\mathrm{Cu}$ complexes and $\mathrm{CuO}$

catalyst shows good structural reversibility upon potential cycling. When the electrode potential is negatively polarized toward $-1.06 \mathrm{~V}$, the amplitude of the $\mathrm{Cu}-\mathrm{Cu}$ peak in the EXAFS spectrum increases, indicating gradual formation of metallic $\mathrm{Cu}$ species (Fig. 2c). At $-1.06 \mathrm{~V}$, in addition to the $\mathrm{Cu}-\mathrm{Cu}$ peak, which has reached its maximum amplitude, there remain peak features in the $R=1 \sim 2 \AA$ range, which can be assigned to the $\mathrm{CuPc}$ structure. This suggests that a possible combination of metallic $\mathrm{Cu}$ and $\mathrm{CuPc}$ molecules exists at the working potential and is consistent with the coexistence of $\mathrm{Cu}(0)$ and $\mathrm{Cu}(\mathrm{II})$ observed in the XANES spectra. The EXAFS spectrum of the
CuPc catalyst at the final $0.64 \mathrm{~V}$ highly resembles that at the initial OCV (Fig. 2c).

Ex situ XRD and SEM characterizations. The structural changes are also reflected in ex-situ X-ray diffraction (XRD) and scanning electron microscopy (SEM) characterizations. After the in-situ XAS measurements, the HKUST-1 and $[\mathrm{Cu}($ cyclam $)] \mathrm{Cl}_{2}$ catalyst electrodes have lost the diffraction patterns of the original $\mathrm{Cu}$ complex materials, but exhibit diffraction peaks of $\mathrm{Cu}_{2} \mathrm{O}$ and $\mathrm{Cu}$, respectively (Fig. 3a, b). Concomitantly, SEM imaging reveals 

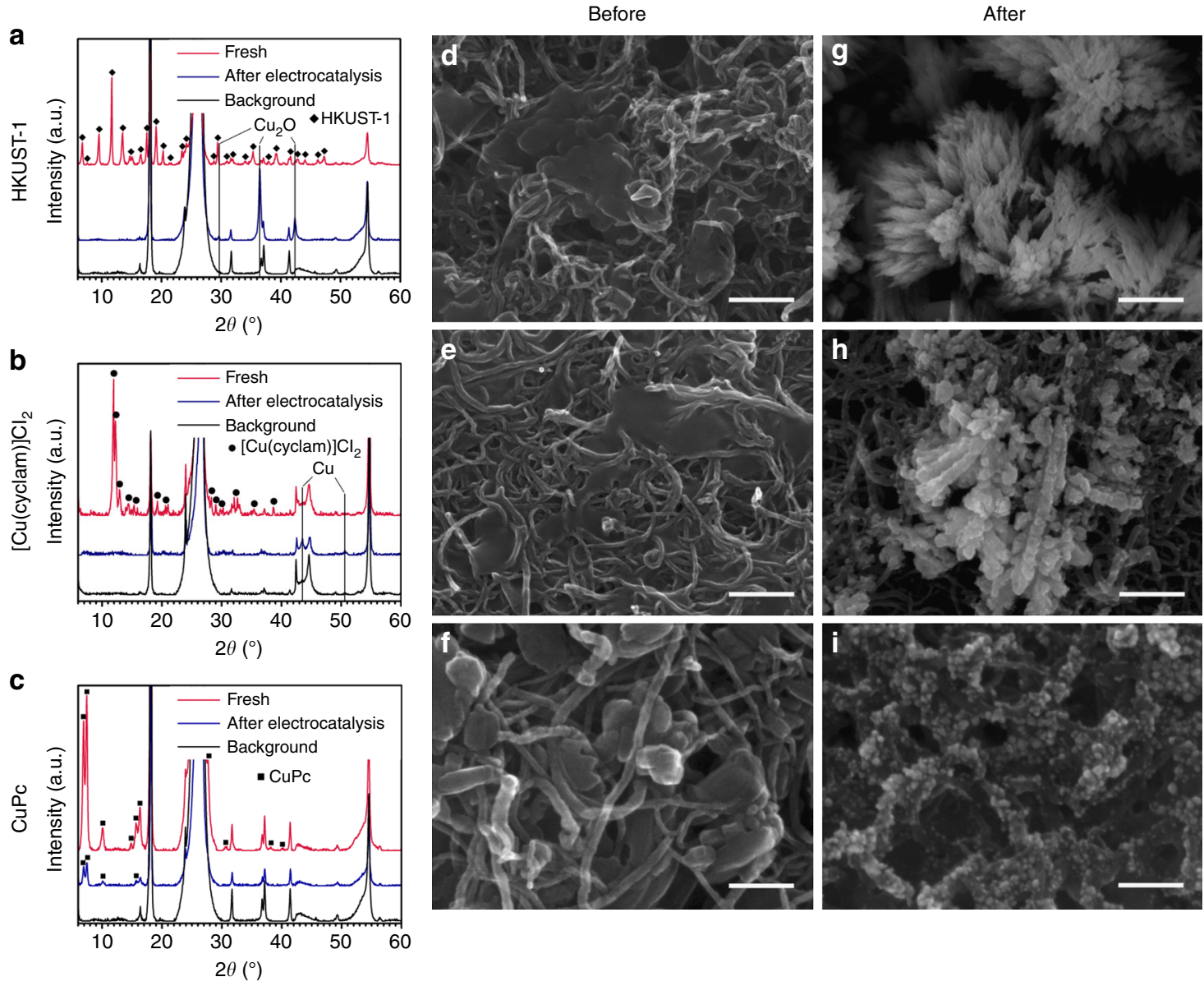

Fig. 3 XRD and SEM characterizations of the three catalyst materials before and after electrolysis. XRD patterns of a HKUST-1, $\mathbf{b}[C u(c y c l a m)] C l_{2}$, and $\mathbf{c}$ CuPc before and after electrocatalysis. The background diffraction patterns are from carbon paper substrates. SEM images of the $\mathbf{d}, \mathbf{g}$ HKUST-1, e, $\mathbf{h}[\mathrm{Cu}$ (cyclam) $\mathrm{Cl}_{2}$, and $\mathbf{f}$, i CuPc catalyst materials $\mathbf{d}-\mathbf{f}$ before and $\mathbf{g}$-i after electrocatalysis. Scale bars: d, e, g, h $200 \mathrm{~nm}$ and $\mathbf{f}, \mathbf{i} 100 \mathrm{~nm}$

morphological changes from the original submicron-sized particles (Fig. 3d, e) to the final dendritic nanostructures (Fig. 3g, h). Unlike HKUST-1 and $[\mathrm{Cu}($ cyclam $)] \mathrm{Cl}_{2}$, the CuPc catalyst electrode shows no existence of $\mathrm{Cu}_{2} \mathrm{O}$ or $\mathrm{Cu}$ (Fig. 3c), agreeing with the in-situ XAS results that the $\mathrm{CuPc}$ structure is recovered after the working electrode potential is returned to $0.64 \mathrm{~V}$. The remaining $\mathrm{CuPc}$ diffraction peaks are likely due to the remaining $\mathrm{CuPc}$ crystals that have not experienced restructuring. It is interesting to note that the cycled $\mathrm{CuPc}$ electrode features a microstructure of $\sim 10 \mathrm{~nm}$-sized nanoparticles well dispersed on the surface of CNTs (Fig. 3i), obviously different from that of the original CuPc (Fig. 3f). The observed morphological changes are a result of the restructuring processes taking place during the potential cycle even though the original $\mathrm{CuPc}$ molecular structure is recovered after the cycle.

EXAFS modeling and analysis. To gain further insights into the restructuring of the $\mathrm{CuPc}$ catalyst under the electrochemical $\mathrm{CO}_{2}$ reduction reaction conditions, we performed model-based analysis to quantify the in-situ EXAFS results. The fitted spectra are shown in Fig. 4a, b and Supplementary Fig. 7, and the fitting parameters related to the major scattering paths (Supplementary Fig. 8) are listed in Supplementary Table 1. Independent parameters of coordination number $(\mathrm{CN})$ are assigned to every scattering path for each spectrum separately. As shown in Supplementary Table 1 , the $\mathrm{Cu}-\mathrm{N}$ and $\mathrm{Cu}-\mathrm{C}$ (belonging to $\mathrm{CuPc}$ ) $\mathrm{CNs}$ decrease quickly while the $\mathrm{Cu}-\mathrm{Cu}$ (belonging to metallic $\mathrm{Cu}$ ) $\mathrm{CNs}$ gradually increase with the decrease of the applied potential.
Negligible changes in the scattering path lengths are found. No $\mathrm{Cu}$ metal components can be fitted into the EXAFS spectra recorded at potentials of $-0.36 \mathrm{~V}$ or higher. At -0.66 and $-0.76 \mathrm{~V}$, small $\mathrm{Cu}-\mathrm{Cu} \mathrm{CNs}$ are obtained. Much larger $\mathrm{Cu}-\mathrm{Cu}$ $\mathrm{CNs}$ are obtained as the potential is switched to $-0.86 \mathrm{~V}$ or lower. As the potential is switched back to $0.64 \mathrm{~V}$, the CuPc component starts to dominate the spectrum again with the $\mathrm{CNs}$ recovered to the values obtained under the initial OCV conditions. The potential-dependent first-shell $\mathrm{Cu}-\mathrm{Cu} \mathrm{CNs}$ are plotted in Fig. 4c. In combination with the above XANES analysis, the EXAFS fitting results can be rationalized as follows. The CuPc structure is predominant at OCV and $-0.36 \mathrm{~V}$. At -0.66 and $-0.76 \mathrm{~V}$, the $\mathrm{CuPc}$ structure starts to change with the $\mathrm{Cu}(\mathrm{II})$ partially reduced to $\mathrm{Cu}(\mathrm{I})$ and thus the $\mathrm{CuPc} C \mathrm{CN}$ decrease but almost no $\mathrm{Cu}(0)$ component is observed. At $-0.86 \mathrm{~V}$ or lower potentials, $\mathrm{Cu}(\mathrm{II})$ and $\mathrm{Cu}(\mathrm{I})$ are converted to $\mathrm{Cu}(0)$ and the metallic $\mathrm{Cu}$ phase nucleates and grows as evidenced by the increasing $\mathrm{Cu}-\mathrm{Cu} \mathrm{CNs}$. The overall consistency between the XANES and EXAFS analysis demonstrates the validity of our results on the restructuring of the $\mathrm{CuPc}$ electrocatalyst under the $\mathrm{CO}_{2}$ reduction conditions.

We further determine the size of the metallic $\mathrm{Cu}$ species reversibly generated by $\mathrm{CuPc}$ under the electrochemical conditions. As $\mathrm{CNs}$ are sensitive to particle size in the nanometer regime ${ }^{39,40}$, it is possible to estimate the size of the formed metallic $\mathrm{Cu}$ species based on the $\mathrm{Cu}-\mathrm{Cu} \mathrm{CNs}$. Following the strategy in the previous reports ${ }^{39,40}$, we built a cuboctahedral model (typically adopted for face-centered cubic metal nanoparticles) ${ }^{41}$ to obtain the size-dependent $\mathrm{Cu}-\mathrm{Cu} \mathrm{CNs}$ (Supplementary 

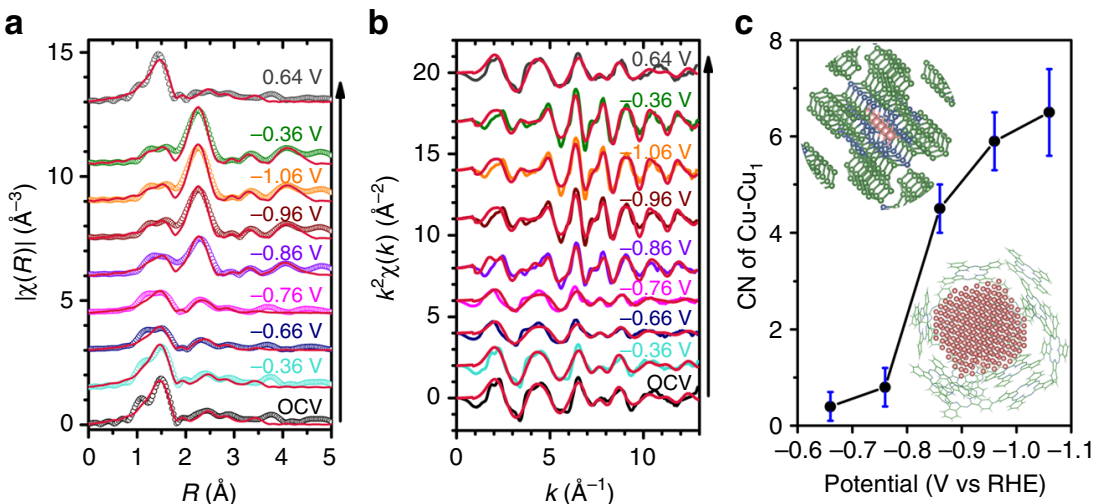

Fig. 4 Fitting results of the EXAFS spectra of the CuPc catalyst at different potentials in $\mathrm{CO}_{2}$-saturated $0.5 \mathrm{M}$ aqueous $\mathrm{KHCO}_{3}$. Fitted $\mathbf{a}$ R-space and $\mathbf{b}$ kspace EXAFS spectra (red traces) of the CuPc catalyst. The experimental data are also plotted for comparison. c First-shell Cu-Cu CNs of the CuPc catalyst at different potentials. The upper left inset shows the CuPc crystal structure, and the lower right inset illustrates a possible configuration of the $\mathrm{Cu}$ nanoclusters generated under the electrocatalytic conditions. Color key: green $-\mathrm{C}$; blue $-\mathrm{N}$; pink- $\mathrm{Cu}$. Error bars represent the uncertainty of $\mathrm{CN}$ determination from the EXAFS analysis

Fig. 9, Supplementary Table 2). As metallic $\mathrm{Cu}$ and $\mathrm{CuPc}$ coexist on the electrode, the compositional change would also affect the nominal $\mathrm{Cu}-\mathrm{Cu} \mathrm{CNs}$ derived from the XAS analysis ${ }^{42}$. We thus performed linear combination fitting for the XAS spectra at $-1.06 \mathrm{~V}$ using the reference spectra of $\mathrm{Cu}$ foil and $\mathrm{CuPc}$ powder. (Supplementary Fig. 10). It shows that there are approximately $20 \%$ of $\mathrm{CuPc}$ and $80 \%$ of metallic $\mathrm{Cu}$ in atomic ratio at $-1.06 \mathrm{~V}$. The measured $\mathrm{CNs}$ were then corrected using this ratio for the compositional effect. By comparing the CNs of the cuboctahedral model nanoparticles with the corrected $\mathrm{CNs}$, we are able to estimate the size of the metallic $\mathrm{Cu}$ species formed at $-1.06 \mathrm{~V}$ vs RHE to be $2 \pm 1 \mathrm{~nm}$. Taken together, our results depict a clear picture for the restructuring-induced electrocatalytic activity of $\mathrm{CuPc}$. At $-0.86 \mathrm{~V}, \mathrm{Cu}$ nanoclusters start to form from $\mathrm{CuPc}$ demetallation. At the optimum working potential of $-1.06 \mathrm{~V}$ where the highest $\mathrm{CO}_{2}$-to- $\mathrm{CH}_{4}$ Faradaic efficiency is achieved, the $\mathrm{Cu}$ nanoclusters reach an average size of $\sim 2 \mathrm{~nm}$. The corresponding $\mathrm{CH}_{4}$ production rate and turnover frequency (TOF) are $3.2 \mathrm{mmol} \mathrm{s}^{-1} \mathrm{~g}_{\mathrm{Cu}}{ }^{-1}$ and 0.39 molecules s${ }^{-1}$ site $^{-1}$, respectively. Given the known properties of metallic $\mathrm{Cu}$ for electrochemically reducing $\mathrm{CO}_{2}$ to hydrocarbons, it is reasonable to believe that the $\mathrm{Cu}$ nanoclusters generated from $\mathrm{CuPc}$ under the working conditions are most likely the active species for the catalysis. The small size of the $\mathrm{Cu}$ nanoclusters generated in-situ appears to be a major contributor to the high current density and selectivity of the CuPc catalyst for electrochemical $\mathrm{CO}_{2}$ conversion to $\mathrm{CH}_{4}$. Although the size dependence of electrochemical $\mathrm{CO}_{2}$ reduction catalyzed by $\mathrm{Cu}$ nanoparticles is still under some debate, more studies appear to support the conclusion that smaller particle sizes and more low-coordination surface sites favor $\mathrm{CO}_{2}$ reduction to $\mathrm{CH}_{4}{ }^{43-45}$. Shape could be another structural factor responsible for the observed catalytic properties ${ }^{4,46-50}$, although at the current stage analyzing the shape of the $2 \mathrm{~nm}$-sized $\mathrm{Cu}$ clusters existing under electrochemical conditions is beyond our capability.

\section{Discussion}

$\mathrm{CuPc}$ exhibits a different restructuring behavior and thus different catalytic properties from HKUST-1 and $[\mathrm{Cu}(\mathrm{cyclam})] \mathrm{Cl}_{2}$. $\mathrm{CuPc}$ reversibly forms $\mathrm{Cu}$ nanoclusters under the reaction conditions, whereas the latter two irreversibly decompose to form dendritic $\mathrm{Cu}$ nanostructures with much larger sizes. Consequently, the $\mathrm{CuPc}$ catalyst shows a lower overpotential, higher selectivity, and larger current density for electrochemical $\mathrm{CO}_{2}$ conversion to $\mathrm{CH}_{4}$. We also find that our previously reported $\mathrm{Cu}$ porphyrin catalyst operates following a similar reversible restructuring scheme as the $\mathrm{CuPc}$ (Supplementary Fig. 11) ${ }^{15}$. To understand more about the distinct restructuring behavior of $\mathrm{CuPc}$, we performed density functional theory (DFT) calculations on the thermodynamics of the reductive demetallation and recovery of the molecular $\mathrm{CuPc}$ structure. Plausible thermodynamic pathways (Supplementary Note 1,2) are constructed for the two processes. The calculation results reveal that the standard reduction potential of $\mathrm{CuPc}$ demetallation is $0.23 \sim 0.35$ and 0.53 $\mathrm{V}$ more negative than those for $[\mathrm{Cu}(\text { cyclam })]^{2+}$ and HKUST-1, respectively (Supplementary Table 3), pointing to the higher thermodynamic stability of the $\mathrm{CuPc}$ structure than the other $\mathrm{Cu}$ complexes. The reversible $\mathrm{Cu}$ nanocluster formation in the $\mathrm{CuPc}$ case is rationalized on the basis of the intrinsic instability of the small nanoclusters. The critical diameter of a $\mathrm{Cu}$ nanocluster, below which the reverse reaction of the $\mathrm{CuPc}$ demetallation process can be spontaneous under OCV conditions, is calculated to be $14 \mathrm{~nm}$. These thermodynamic calculations suggest that the metal ion-ligand binding affinity of a $\mathrm{Cu}$ complex influences the threshold potential as well as the reversibility of the reductive demetallation process. Although these results are qualitatively consistent with our experimental observations, we note that the restructuring process may involve other important factors such as the solubility of the demetallated ligand and the electronic structure of the complex. With the speculation that the demetallated phthalocyanine ligands must be in the vicinity of the $\mathrm{Cu}$ nanoclusters, we sketched a schematic model (Fig. 4c lower right inset) to qualitatively illustrate a possible spatial configuration of the active species derived from CuPc (Fig. 4c upper left inset) under the working conditions. The presence of the ligands may be an important contributor to the observed reversible restructuring behavior and high catalytic activity for $\mathrm{CO}_{2}$ conversion to $\mathrm{CH}_{4}{ }^{51,52}$.

Restructuring of $\mathrm{Cu}$ complexes in electrocatalytic materials for $\mathrm{CO}_{2}$ reduction to $\mathrm{CH}_{4}$ has been elucidated by in-situ and operando XAS characterization of representative $\mathrm{Cu}$ complex structures $\left(\mathrm{CuPc}, \mathrm{HKUST}-1\right.$ and $\left.[\mathrm{Cu}(\mathrm{cyclam})] \mathrm{Cl}_{2}\right)$ probed under electrochemical reaction conditions. The highest activity and selectivity of $\mathrm{CuPc}$ for catalyzing $\mathrm{CO}_{2}$-to- $\mathrm{CH}_{4}$ conversion among the three structures has been explained by its reversible restructuring to form $\sim 2 \mathrm{~nm}$ metallic $\mathrm{Cu}$ nanoclusters, which are identified as the active sites for the electrocatalysis. Our findings suggest the possibility of controlling catalytic active sites through 
molecular structure design, providing insights into strategies for developing high-performance electrocatalyst materials.

\begin{abstract}
Methods
Materials. Nafion perfluorinated resin solution (5 wt\% in lower aliphatic alcohols and water), $\mathrm{KHCO}_{3}$ (ACS Reagent 99.7\%), and $\mathrm{H}_{3} \mathrm{PO}_{4}$ (ACS Reagent $\geq 85 \%$ ) were purchased from Sigma Aldrich. Graphite rod (99.9995\%) and Ti foil $(0.127 \mathrm{~mm}$, 99.99\%) were purchased from Alfa Aesar. CuPc (dye content 99.13\%) was purchased from Acros Organics. $\mathrm{HCl}$ (ACS Reagent $36.5 \sim 38 \%$ ) was purchased from J.T. Baker. All materials were used as obtained without further purification. Deionized water (Milli-Q Millipore $18.2 \mathrm{M} \Omega \mathrm{cm}^{-1}$ ) was used throughout all the experiments
\end{abstract}

HKUST-1 synthesis. To synthesize HKUST-1, a solution of $0.252 \mathrm{~g}$ of $\mathrm{H}_{3} \mathrm{btc}(1.2$ $\mathrm{mmol}$ ) in $12 \mathrm{ml}$ of water/ethanol (volume ratio=2:1) was rapidly added into a solution of $\mathrm{Cu}\left(\mathrm{NO}_{3}\right)_{2} \cdot 3 \mathrm{H}_{2} \mathrm{O}(0.145 \mathrm{~g}, 0.6 \mathrm{mmol})$ in $12 \mathrm{ml}$ of water under vigorous magnetic stirring $(1200 \mathrm{rpm})$. The mixture was kept under the stirring condition for $120 \mathrm{~min}$ at room temperature. The product was collected by repeated ethanol wash and centrifugation for more than five times until the supernatant was colorless. The final product was lyophilized. XRD pattern of HKUST-1 powder is shown in Supplementary Fig. 12.

$[\mathrm{Cu} \text { (cyclam) }]_{\mathrm{Cl}_{2}}$ synthesis. The preparation of $[\mathrm{Cu}($ cyclam $)] \mathrm{Cl}_{2}$ is shown in Supplementary Note 3 . The copper salt was used in slightly less amount $(0.93 \mathrm{eq}$ relative to cyclam), to ensure the complete consumption of copper ion, thus to ensure the absence of copper ion in the final product. The excess cyclam was removed by recrystallization from isopropanol. To synthesize $[\mathrm{Cu}(\mathrm{cyclam})] \mathrm{Cl}_{2}, \mathrm{~A}$ solution of 1,4,8,11-tetraazacyclotetradecane (cyclam, $150 \mathrm{mg}, 0.75 \mathrm{mmol}$ ) in ethanol $(20 \mathrm{ml})$ was added $\mathrm{CuCl}_{2} \cdot 2 \mathrm{H}_{2} \mathrm{O}(121 \mathrm{mg}, 0.70 \mathrm{mmol}, 0.93 \mathrm{eq})$ in one portion. The color changed immediately from colorless to purple. The resulting solution was stirred at $80^{\circ} \mathrm{C}$ under nitrogen atmosphere. After $5 \mathrm{~h}$, the solution was cooled to room temperature and then filtered through a filter paper to remove the insoluble material, whereupon ethanol was removed by rotary evaporation. Isopropanol $(\sim 40 \mathrm{ml})$ was then added to the purple residue and the mixture was heated to reflux to completely dissolve the solid. The resulting purple solution was placed in a freezer $\left(-20^{\circ} \mathrm{C}\right)$ overnight, and the precipitated solid was collected by centrifugation and dried under high vacuum to afford $[\mathrm{Cu}(\mathrm{cyclam})] \mathrm{Cl}_{2}(228 \mathrm{mg}$, $90 \%$ yield) as a purple powder. The $\mathrm{UV}-\mathrm{Vis}$ absorption spectrum of [ $\mathrm{Cu}$ (cyclam)] $\mathrm{Cl}_{2}$ in $\mathrm{CH}_{3} \mathrm{OH}$ is shown in Supplementary Fig. 13. High-resolution MS (electrospray) $\mathrm{m} / z(\mathrm{M}-2 \mathrm{Cl})^{2+}$ calcd for $\mathrm{C}_{12} \mathrm{H}_{28} \mathrm{CuCl}_{2} \mathrm{~N}_{4}$ 146.58, found 146.56; $\lambda_{\max }\left(\mathrm{CH}_{3} \mathrm{OH}\right) 260,528 \mathrm{~nm}$.

Characterizations. SEM measurements were performed with a Hitach SU8230 cold field emission SEM microscope. XRD patterns were collected with a Rigaku SmartLab X-ray Diffractometer equipped with a $\mathrm{Cu}$-target X-ray tube $(\lambda=0.154 \mathrm{~nm})$ and operated at $40 \mathrm{~mA}$ and $44 \mathrm{kV}$. Absorption spectra were recorded on a Varian Cary 50 Bio UV-visible spectrophotometer. The mass spectral data were obtained from a Thermo Scientific LTQ Orbitrap ELITE mass spectrometer. The sample was directly infused into the mass spectrometry via a syringe pump at $5 \mu \mathrm{min}^{-1}$.

Electrochemical measurements. Electrochemical experiments were performed on a Bio-Logic VMP3 Multi Potentiostat using a home-made gas-tight twocompartment electrochemical cell. Two milligrams of catalyst materials and $2 \mathrm{mg}$ of mildly oxidized multi-wall CNTs were mixed with $12 \mu \mathrm{l}$ of $5 \mathrm{wt} \%$ Nafion solution and $2 \mathrm{ml}$ of methanol by sonication for more than $30 \mathrm{~min}$ to form homogeneous inks. The CNTs were prepared following a modified Hummers method as described in our previous work ${ }^{20}$. For each material, $7.5 \mu \mathrm{l}$ of the ink was dropped onto a well-polished glassy carbon disk electrode (diameter: $4 \mathrm{~mm}$ ) and allowed to dry. The catalyst mass loading was $60 \mu \mathrm{g} \mathrm{cm}^{-2}$. A graphite rod and a $\mathrm{Ag} / \mathrm{AgCl}$ electrode were used as the counter and reference electrodes. The working electrode compartment and the counter electrode compartment were separated by an anion exchange membrane (Selemion DSV). Each compartment contained $12 \mathrm{ml}$ of electrolyte and $\sim 18 \mathrm{ml}$ of gas headspace. Pre-purified $0.5 \mathrm{M} \mathrm{KHCO}_{3}$ aqueous solution was used as the electrolyte for all experiments. The electrolyte was purified following a method described in our previous work ${ }^{15}$. Before measurement, the electrolyte was pre-saturated with $\mathrm{CO}_{2}$ by bubbling the gas for $15 \mathrm{~min}$. During measurement, $\mathrm{CO}_{2}$ was continuously bubbled into the electrolyte at a flow rate of 10 s.c.c.m. Current densities were normalized to the geometric area of the glassy carbon electrode. All potentials were referred to the RHE and were recorded with iR compensation.

Product quantification. Gas products of electrocatalysis were analyzed by a GC (SRI Multiple Gas Analyzer \#5) equipped with molecular sieve 5A and HayeSep D columns with $\mathrm{N}_{2}$ as the carrier gas. Hydrogen was analyzed by a thermal conductivity detector, and carbon monoxide, methane, and ethylene were determined using a flame ionization detector. The peak areas were converted to gas volumes using calibration curves. Liquid products were quantified after electrocatalysis by
${ }^{1} \mathrm{H}$ NMR (V600a Varian VNMRS $600 \mathrm{MHz}$ NMR). Electrolyte (700 $\mu \mathrm{l}$ ) was mixed with $35 \mu \mathrm{l}$ of $10 \mathrm{mM}$ dimethyl sulfoxide and $50 \mathrm{mM}$ phenol as internal standards in $\mathrm{D}_{2} \mathrm{O}$ for the ${ }^{1} \mathrm{H}$ NMR analysis.

In-situ and operando XAS measurements. In-situ XANES and EXAFS experiments were carried out at beamline 5BM-D of DND-CAT, Advanced Photon Source, Argonne National Laboratory. The working electrodes were prepared by depositing catalysts on $\sim 100 \mu$ m-thick carbon fiber paper. For HKUST-1 and CuPc, $6.4 \mathrm{mg}$ of material and $1.6 \mathrm{mg}$ of CNTs were mixed with $48 \mu \mathrm{l}$ of $5 \mathrm{wt} \%$ Nafion solution and $2 \mathrm{ml}$ of methanol by sonication for more than $30 \mathrm{~min}$ to form a homogeneous ink, and then $140 \mu \mathrm{l}$ of the ink was drop-dried onto a $2.5 \times 1.5 \mathrm{~cm}^{2}$ carbon fiber paper (Toray030-30\%PTFE) to form a $0.5 \times 1 \mathrm{~cm}^{2}$ active area (corresponding to a catalyst mass loading of $\left.1.8 \mathrm{mg} \mathrm{cm}^{-2}\right)$. For $[\mathrm{Cu}(\mathrm{cyclam})] \mathrm{Cl}_{2}, 140 \mu \mathrm{l}$ of a CNT ink ( $1.6 \mathrm{mg}$ of CNTs mixed with $6.4 \mu \mathrm{l}$ of $5 \mathrm{wt} \%$ Nafion solution and $2 \mathrm{ml}$ of methanol by sonication for more than $30 \mathrm{~min}$ ) was drop-dried onto a $2.5 \times 1.5$ $\mathrm{cm}^{2}$ carbon fiber paper (GDS1120) to form a $0.5 \times 1 \mathrm{~cm}^{2}$ area, and then $140 \mu \mathrm{l}$ of $3.2 \mathrm{mg} \mathrm{ml}^{-1}$ methanol solution of $[\mathrm{Cu}(\mathrm{cyclam})] \mathrm{Cl}_{2}$ was drop-dried onto the CNT area (corresponding to a catalyst mass loading of $1.8 \mathrm{mg} \mathrm{cm}^{-2}$ ). The catalyst electrode was mounted onto a custom-designed in-situ XAS fluorescence cell (Supplementary Fig. 3), as described in our previous study ${ }^{5,35}$. The cell which can contain up to $30 \mathrm{~mL}$ of electrolyte was set in a three-electrode configuration. A graphite rod and a $\mathrm{Ag} / \mathrm{AgCl}$ electrode were used as the counter and reference electrodes, respectively. The same electrolyte was used as described in the Electrochemical measurements session. During the in-situ and operando XAS measurements, $\mathrm{CO}_{2}$ was constantly bubbled at a flow rate of 30 s.c.c.m. All data were collected in a fluorescence mode under various applied potentials controlled by a Gamry Reference-600 electrochemical workstation. A Vortex ME4 detector was used to collect the $\mathrm{Cu} \mathrm{K}$ fluorescence signal while a $\mathrm{Si}(111)$ monochromator scanned the incident X-ray photon energy through the $\mathrm{Cu} \mathrm{K}$ absorption edge. The monochromator was detuned to $65 \%$ of the maximum intensity at the $\mathrm{Cu} \mathrm{K}$ edge to minimize the presence of higher harmonics. Each selected potential (iR compensated) was held until enough data statistics of XAS were achieved. The X-ray beam was calibrated using a Cu metal foil. Data reduction, data analysis, and EXAFS fitting were performed with the Athena, Artemis, and IFEFFIT software packages. Standard procedures were used to extract the EXAFS data from the measured absorption spectra. The pre-edge background was linearly fitted and subtracted. The post-edge background was determined using a cubic-spline-fit procedure and then subtracted. Normalization was performed by dividing the data by the height of the absorption edge at $50 \mathrm{eV}$. For quantitative analysis, phase shifts and backscattering amplitudes were generated by the FEFF calculations based on crystal structures of $\mathrm{Cu}$ and $\mathrm{CuPc}$, and were then calibrated through performing the FEFFIT of the EXAFS data of the reference samples, mainly to obtain the amplitude reduction factor $\left(\mathrm{S}_{0}{ }^{2}\right)$ values. With $\mathrm{S}_{0}{ }^{2}$ known, the EXAFS data of the catalyst materials were fitted with such generated phase shifts and amplitudes. Accuracies of the obtained results presented here are as follows: $\Delta N( \pm 10 \%), \Delta R( \pm 1 \%), \Delta \sigma^{2}$ $( \pm 10 \%)$, and $\Delta E_{0}( \pm 10 \%)^{34,53,54}$.

EXAFS modeling and analysis. The EXAFS data of $\mathrm{Cu}$ foil and $\mathrm{CuPc}$ powder were fitted (Supplementary Fig. 7) and the obtained $\mathrm{S}_{0}^{2}$ values were used as references to calculate the CNs in the analysis of the in-situ EXAFS data. As the in-situ XANES and EXAFS spectra of $\mathrm{CuPc}$ show coexistence of $\mathrm{Cu}(0)$ and $\mathrm{Cu}(\mathrm{II})$ at several applied potentials, it is natural to use the scattering paths from $\mathrm{Cu}$ metal and $\mathrm{CuPc}$ crystal structures to fit the in-situ EXAFS spectra. To reduce the number of fitting parameters and to increase the information content, co-refinement of a total of 9 EXAFS data sets was performed. Many parameters such as mean-square disorder $\left(\sigma^{2}\right)$, energy shift $\left(E_{0}\right)$, and scattering path length change $\left(\Delta R\right.$ or $\alpha$ in $\left.\alpha^{*} R\right)$ are shared across all the data sets, and only the CNs for each scattering path in each data set are independent and separated. This results in 50 fitting parameters for a total of 175 independent variables. For each data set, there is an average of less than 6 fitting parameters, much less than what is used in conventional EXAFS fitting. All of these fitting parameters were used without any particular constraints. Fitting was done through three shells by taking into account multiple-scattering paths but only the major single scattering paths, namely $\mathrm{Cu}-\mathrm{N}_{1}, \mathrm{Cu}-\mathrm{C}_{1}$, and $\mathrm{Cu}-\mathrm{N}_{2}$ for $\mathrm{CuPc}$, as well as $\mathrm{Cu}-\mathrm{Cu}_{1}, \mathrm{Cu}-\mathrm{Cu}_{2}$, and $\mathrm{Cu}-\mathrm{Cu}_{3}$ for $\mathrm{Cu}$, illustrated in Supplementary Fig. 8, are listed in Supplementary Table 1.

Linear combination fit. Owing to the ensemble average nature of XAS measurements, it is possible to perform a linear combination fit $^{34}$ using the reference spectra of $\mathrm{Cu}$ foil and $\mathrm{CuPc}$ powder to obtain the percentages of $\mathrm{Cu}$ nanoclusters and remaining $\mathrm{CuPc}$ in the catalyst material. A fit of the XANES spectrum at $1.06 \mathrm{~V}$ overestimates the content of $\mathrm{CuPc}$ as the characteristic $\mathrm{Cu}(\mathrm{II})$ peak of the fitted spectrum is much higher in intensity than that of the measured spectrum (Supplementary Fig. 10A). A fit of the EXAFS spectrum (Supplementary Fig. 10B) gives $13 \%$ of $\mathrm{CuPc}$ and $87 \%$ of metallic $\mathrm{Cu}$. This might have slightly overestimated the metallic $\mathrm{Cu}$ content as in our case there are $\mathrm{Cu}$ nanoclusters which have smaller average CNs compared with bulk $\mathrm{Cu}$ metal. Furthermore, the CNs of bulk materials in a mixture can reflect their concentrations ${ }^{42}$. The EXAFS analysis show that at $-1.06 \mathrm{~V}$ the $\mathrm{CN}$ of $\mathrm{Cu}-\mathrm{N}_{1}$ is $1.2 \pm 0.5$, which suggests that the CuPc content is $30 \% \pm 12.5 \%$ as the theoretical first shell $\mathrm{CN}$ of CuPc is 4 . Having taken all the 
results into consideration, we estimate that the $\mathrm{CuPc}$ catalyst material at $-1.06 \mathrm{~V}$ contains approximately $20 \%$ of $\mathrm{CuPc}$ and $80 \%$ of metallic $\mathrm{Cu}$ by atomic ratio.

\section{Estimation of Cu nanocluster size at $\mathbf{- 1 . 0 6} \mathbf{~ V}$. Nearest-neighbor CNs of} nanoclusters are dependent on cluster sizes. The CNs are nonlinear functions of the cluster diameter if the latter is smaller than $3-5 \mathrm{~nm}^{39}$. This property is widely used in EXAFS analyses to determine nanocluster size $e^{39,40,55,56}$. Using the $\mathrm{Cu}$ cuboctahedral model (Supplementary Fig. 9A) and the strategy reported before ${ }^{39}$, we calculated the size-dependent CNs of several scattering paths, as shown in Supplementary Fig. 9B and also listed in Supplementary Table 2. Considering the compositional effect, we scaled the CNs obtained in our EXAFS fits to estimate the nanocluster size ${ }^{42}$. For example, at $-1.06 \mathrm{~V}$, the $\mathrm{CNs}$ of $\mathrm{Cu}-\mathrm{Cu}_{1}, \mathrm{Cu}_{-}-\mathrm{Cu}_{2}$, and $\mathrm{Cu}-$ $\mathrm{Cu}_{3}$ are $6.5,1.4$, and 15.8 , respectively. Considering that there are $80 \%$ of $\mathrm{Cu}$ nanoclusters in the catalyst material, the true $\mathrm{CNs}$ of the $\mathrm{Cu}$ nanoclusters should be $8.1,1.8$ and 19.8, respectively. By checking Supplementary Table 2, these CN values correspond to roughly $1,0.5$, and $4 \mathrm{~nm}$. Considering the errors associated with the obtained $\mathrm{CN}$ values, we estimate that the average size of the $\mathrm{Cu}$ nanoclusters formed at $-1.06 \mathrm{~V}$ is $2 \pm 1 \mathrm{~nm}$.

TOF calculation. To calculate the TOF for the CuPc catalyst, the number of surface sites was estimated based on the size and geometry of the metallic Cu clusters using the equation below:

$$
\mu=M N=M \frac{\alpha m N_{\mathrm{A}}}{M_{\mathrm{CuPc}}}
$$

Where $\mu$ denotes the number of surface sites, $M$ denotes the percentage of surface $\mathrm{Cu}$ atoms in a Cu cluster, $N$ denotes the total number of $\mathrm{Cu}$ atoms in all the $\mathrm{Cu}$ clusters on the electrode, $\alpha$ denotes the percentage of $\mathrm{CuPc}$ molecules that have restructured to $\mathrm{Cu}$ clusters, $m$ denotes the original mass loading of $\mathrm{CuPc}$ $\left(60 \mu \mathrm{g} \mathrm{cm}^{-2}\right), N_{\mathrm{A}}$ denotes the Avogadro constant $\left(6.022 \times 10^{23}\right)$, and $M_{\mathrm{CuPc}}$ denotes the molecular mass of CuPc $\left(576.07 \mathrm{~g} \mathrm{~mol}^{-1}\right)$. Here, $\alpha=80 \%$ based on the XAS results. Consider that the $\mathrm{Cu}$ clusters are $2 \mathrm{~nm}$ cuboctahedra containing 162 surface $\mathrm{Cu}$ atoms and a total of $309 \mathrm{Cu}$ atoms, $M=0.524$. Consequently, $\mu=2.63 \times 10^{16}$ sites per $\mathrm{cm}^{2}$. TOF was calculated using the equation below:

$$
\mathrm{TOF}=\frac{j}{n e \mu}
$$

Where $j$ is the partial current density for $\mathrm{CH}_{4}$ formation, $n$ is the number of electrons needed to reduce one $\mathrm{CO}_{2}$ molecule to $\mathrm{CH}_{4}$, and $e$ is the elementary charge. $j, n$, and $e$ are $13 \mathrm{~mA} \mathrm{~cm}^{-2}, 8$, and $1.602 \times 10^{-19} \mathrm{C}$, respectively. Therefore, the TOF of $\mathrm{CH}_{4}$ for the CuPc catalyst at $-1.06 \mathrm{~V}$ vs RHE is 0.39 molecules site ${ }^{-1} \mathrm{~s}^{-1}$.

DFT calculations on the thermodynamics of Cu-complex demetallation and remetallation. DFT geometry optimization calculations were performed using the hybrid functional B3LYP, which includes Becke's three parameter exchange ${ }^{57}$ and the Lee, Yang and Parr correlation ${ }^{58}$ as implemented in Gaussian 09 (Rev. D.01) ${ }^{59}$. For optimizations and thermochemistry $(T=298.15 \mathrm{~K})$, we used the basis set 6-31 G(d) ${ }^{60}$ for all atoms. The optimized molecular structures are shown in Supplementary Fig. 14. For single point calculations, we used the basis set def2TZVP ${ }^{60}$ for $\mathrm{Cu}$ atoms and $6-311+\mathrm{G}(2 \mathrm{df}, \mathrm{p})$ for all other atoms ${ }^{61}$. Solvent correction was implemented using the SMD model with water as the solvent ${ }^{62}$. A hypothetical thermodynamic pathway (Supplementary Note 1) under standard conditions is constructed for reductive demetallation which consists of: (1) dissociation and protonation of the ligand and (2) reduction of the hexaaqua $\mathrm{Cu}(\mathrm{II})$ ion into bulk $\mathrm{Cu}$ metal. Through the Nernst equation, the standard reduction potential of deme-

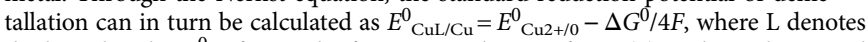
the ligand and $\Delta G^{0}$ refers to the free energy change of step (1) in the pathway and $E^{0}{ }_{\mathrm{Cu} 2+/ 0}$ refers to the standard reduction potential of $\mathrm{Cu}^{2+}$ to $\mathrm{Cu}(0)^{63}$. Supplementary Table 3 lists the $\Delta G^{0}$ values and $E_{\mathrm{CuL} / \mathrm{Cu}}^{0}$ for all of the three Cu-complex structures investigated in the study. Re-metallation of the $\mathrm{Pc}^{2-}$ ligand is considered to be an oxidation of $\mathrm{Cu}$ nanoclusters by $\mathrm{H}_{2} \mathrm{Pc}$, as illustrated by the hypothetical thermodynamic pathway shown in Supplementary Note 2. The change of free energy $(\Delta G)$ for re-metallation is dependent on the size of $\mathrm{Cu}$ nanoparticles and is $7.3 \mathrm{kcal} \mathrm{mol}^{-1}$ for bulk $\mathrm{Cu}$ metal. The size-dependent cohesive energy of $\mathrm{Cu}$ nanoparticles is calculated through the following established equation: ${ }^{64}$

$$
\frac{E_{\mathrm{c}}(D)}{E_{\mathrm{cb}}}=\exp \left(-\frac{2 S_{\mathrm{cb}}}{3 R} \frac{1}{\frac{D}{D_{0}}-1}\right) \times\left(1-\frac{1}{\frac{D}{D_{0}}-1}\right)
$$

where $E_{\mathrm{c}}(D)$ denotes the cohesive energy of a nanoparticle with diameter $D$; $E_{\mathrm{cb}}$ denotes the cohesive energy of the bulk crystal; $D_{0}$ denotes the atomic radius; $R$ is the ideal gas constant; $S_{\mathrm{cb}}$ is defined as $E_{\mathrm{cb}} / T_{\mathrm{cb}}$ where $T_{\mathrm{cb}}$ refers to the boiling point of bulk Cu metal. $D_{0}=0.128 \mathrm{~nm}, E_{\mathrm{cb}}=336 \mathrm{~kJ} \mathrm{~mol}^{-1}$ and $T_{\mathrm{cb}}=2840 \mathrm{~K}$ are taken from the literature ${ }^{65,66}$. The critical diameter of $\mathrm{Cu}$ nanoparticles is defined as the size at which $\Delta G$ of re-metallation is zero. The critical diameter in the case of $\mathrm{CuPc}$ is calculated to be $14.2 \mathrm{~nm}$.
Data availability. The data that support the findings of this study are available within the paper and its Supplementary Information file or are available from the corresponding authors upon reasonable request.

Received: 5 October 2017 Accepted: 2 January 2018

Published online: 29 January 2018

\section{References}

1. Lu, Q. \& Jiao, F. Electrochemical $\mathrm{CO}_{2}$ reduction: electrocatalyst, reaction mechanism, and process engineering. Nano Energy 29, 439-456 (2016).

2. $\mathrm{Wu}, \mathrm{J}$. J. \& $\mathrm{Zhou}, \mathrm{X}$. D. Catalytic conversion of $\mathrm{CO}_{2}$ to value added fuels: Current status, challenges, and future directions. Chin. J. Catal. 37, 999-1015 (2016)

3. Huo, S.-J. et al Coupled metal/oxide catalysts with tunable product selectivity for electrocatalytic $\mathrm{CO}_{2}$ reduction. ACS Appl. Mater. Interfaces $\mathbf{9}$, 28519-28526 (2017).

4. Takeda, H., Cometto, C., Ishitani, O. \& Robert, M. Electrons, photons, protons and earth-abundant metal complexes for molecular catalysis of $\mathrm{CO}_{2}$ reduction. ACS Catal. 7, 70-88 (2017).

5. Wu, Y. et al. Electroreduction of $\mathrm{CO}_{2}$ catalyzed by a heterogenized $\mathrm{Zn}$-porphyrin complex with a redox-innocent metal center. ACS Cent. Sci. 3, 847-852 (2017).

6. Zhang, $\mathrm{X}$. et al. Highly selective and active $\mathrm{CO}_{2}$ reduction electro-catalysts based on cobalt phthalocyanine/carbon nanotube hybrid structures. Nat. Commun. 8, 14675 (2017).

7. Costentin, C., Drouet, S., Robert, M. \& Saveant, J. M. A local proton source enhances $\mathrm{CO}_{2}$ electroreduction to $\mathrm{CO}$ by a molecular Fe catalyst. Science $\mathbf{3 3 8}$, 90-94 (2012).

8. Kornienko, N. et al. Metal-organic frameworks for electrocatalytic reduction of carbon dioxide. J. Am. Chem. Soc. 137, 14129-14135 (2015).

9. Schneider, J. et al. Nickel(II) macrocycles: highly efficient electrocatalysts for the selective reduction of $\mathrm{CO}_{2}$ to CO. Energy Environ. Sci. 5, 9502-9510 (2012).

10. Angamuthu, R., Byers, P., Lutz, M., Spek, A. L. \& Bouwman, E. Electrocatalytic $\mathrm{CO}_{2}$ conversion to oxalate by a copper complex. Science 327, 313-315 (2010).

11. Lin, S. et al. Covalent organic frameworks comprising cobalt porphyrins for catalytic $\mathrm{CO}_{2}$ reduction in water. Science 349, 1208-1213 (2015).

12. Shen, J. et al. Electrocatalytic reduction of carbon dioxide to carbon monoxide and methane at an immobilized cobalt protoporphyrin. Nat. Commun. 6, 8177 (2015).

13. Yao, S. A. et al. Covalent attachment of catalyst molecules to conductive diamond: $\mathrm{CO}_{2}$ reduction using "smart" electrodes. J. Am. Chem. Soc. 134, 15632-15635 (2012)

14. Albo, J. et al. Copper-based metal-organic porous materials for $\mathrm{CO}_{2}$ electrocatalytic reduction to alcohols. ChemSusChem 10, 1100-1109 (2017).

15. Weng, Z. et al. Electrochemical $\mathrm{CO}_{2}$ reduction to hydrocarbons on a heterogeneous molecular $\mathrm{Cu}$ catalyst in aqueous solution. J. Am. Chem. Soc. 138, 8076-8079 (2016).

16. Tanaka, K. Chemical reconstruction and catalysis of metal and bimetallic surfaces. Surf. Sci. 357, 721-728 (1996)

17. Titmuss, S., Wander, A. \& King, D. A. Reconstruction of clean and adsorbatecovered metal surfaces. Chem. Rev. 96, 1291-1305 (1996).

18. Kolb, D. M. Reconstruction phenomena at metal-electrolyte interfaces. Prog. Surf. Sci. 51, 109-173 (1996).

19. Wei, H. S. et al. In situ growth of $\mathrm{Ni}_{\mathrm{x}} \mathrm{Cu}_{1-\mathrm{x}}$ alloy nanocatalysts on redoxreversible rutile $(\mathrm{Nb}, \mathrm{Ti}) \mathrm{O}_{4}$ towards high-temperature carbon dioxide electrolysis. Sci. Rep. 4, 5156 (2014).

20. Weng, Z. et al. Metal/oxide interface nanostructures generated by surface segregation for electrocatalysis. Nano Lett. 15, 7704-7710 (2015).

21. Eren, B. et al. Activation of $\mathrm{Cu}(111)$ surface by decomposition into nanoclusters driven by CO adsorption. Science 351, 475-478 (2016).

22. Karaiskakis, A. N. \& Biddinger, E. J. Evaluation of the impact of surface reconstruction on rough electrodeposited copper-based catalysts for carbon dioxide electroreduction. Energy Technol. 5, 901-910 (2017).

23. Gunathunge, C. M. et al. Spectroscopic observation of reversible surface reconstruction of copper electrodes under $\mathrm{CO}_{2}$ reduction. J. Phys. Chem. C. 121, 12337-12344 (2017)

24. Irvine, J. T. S. et al. Evolution of the electrochemical interface in hightemperature fuel cells and electrolysers. Nat. Energy 1, 15014 (2016).

25. Weng, Z. et al. Self-Cleaning Catalyst Electrodes for Stabilized CO2 Reduction to Hydrocarbons. Angew. Chem. Int. Ed. 56, 13135-13139 (2017).

26. Blakemore, J. D., Crabtree, R. H. \& Brudvig, G. W. Molecular catalysts for water oxidation. Chem. Rev. 115, 12974-13005 (2015).

27. Zhang, X. et al. Iron-doped cobalt monophosphide nanosheet/carbon nanotube hybrids as active and stable electrocatalysts for water splitting. $A d v$ Funct. Mater. 27, 1606635 (2017). 
28. Xu, X., Song, F. \& Hu, X. L. A nickel iron diselenide-derived efficient oxygenevolution catalyst. Nat. Commun. 7, 12324 (2016).

29. Feng, Z. X. et al. Catalytic activity and stability of oxides: the role of near-surface atomic structures and compositions. Acc. Chem. Res. 49, 966-973 (2016).

30. Liu, X. S., Yang, W. L. \& Liu, Z. Recent progress on synchrotron-based in-situ soft X-ray spectroscopy for energy materials. Adv. Mater. 26, 7710-7729 (2014).

31. Stoerzinger, K. A., Hong, W. T., Crumlin, E. J., Bluhm, H. \& Shao-Horn, Y. Insights into electrochemical reactions from ambient pressure photoelectron spectroscopy. Acc. Chem. Res. 48, 2976-2983 (2015).

32. Feng, Z. X. et al. Catalysts transform while molecules react: An atomic-scale view. J. Phys. Chem. Lett. 4, 285-291 (2013).

33. Nilsson, A. et al. Catalysis in real time using X-ray lasers. Chem. Phys. Lett 675, 145-173 (2017).

34. Feng, Z. et al. Atomic-scale cation dynamics in a monolayer $\mathrm{VO}_{\mathrm{x}} / \alpha-\mathrm{Fe}_{2} \mathrm{O}_{3}$ catalyst. RSC Adv. 5, 103834-103840 (2015).

35. Wei, C. et al. Valence change ability and geometrical occupation of substitution cations determine the pseudocapacitance of spinel ferrite $\mathrm{XFe}_{2} \mathrm{O}_{4}$ (X=Mn, Co, Ni, Fe). Chem. Mater. 28, 4129-4133 (2016).

36. Zhang, Y. Q. et al. A rational design for enhanced oxygen reduction: Strongly coupled silver nanoparticles and engineered perovskite nanofibers. Nano Energy 38, 392-400 (2017).

37. Liu, W. et al. A highly active and stable hydrogen evolution catalyst based on pyrite-structured cobalt phosphosulfide. Nat. Commun. 7, 10771 (2016).

38. Fan, Q., Liu, W., Weng, Z., Sun, Y. M. \& Wang, H. L. Ternary hybrid material for high-performance lithium-sulfur battery. J. Am. Chem. Soc. 137, 12946-12953 (2015)

39. Frenkel, A. I. Solving the structure of nanoparticles by multiple-scattering EXAFS analysis. J. Synchrotron Radiat. 6, 293-295 (1999).

40. Frenkel, A. I., Yevick, A., Cooper, C. \& Vasic, R. Modeling the structure and composition of nanoparticles by extended X-ray absorption fine-structure spectroscopy. Annu. Rev. Anal. Chem. 4, 23-39 (2011).

41. Li, Y. M. et al. A Pt-cluster-based heterogeneous catalyst for homogeneous catalytic reactions: $\mathrm{X}$-ray absorption spectroscopy and reaction kinetic studies of their activity and stability against leaching. J. Am. Chem. Soc. 133, 13527-13533 (2011)

42. Carta, D. et al. Structural characterization study of FeCo alloy nanoparticles in a highly porous aerogel silica matrix. J. Chem. Phys. 127, 204705 (2007).

43. Tang, W. et al. The importance of surface morphology in controlling the selectivity of polycrystalline copper for $\mathrm{CO}_{2}$ electroreduction. Phys. Chem. Chem. Phys. 14, 76-81 (2012).

44. Manthiram, K., Beberwyck, B. J. \& Aivisatos, A. P. Enhanced electrochemical methanation of carbon dioxide with a dispersible nanoscale copper catalyst. $J$. Am. Chem. Soc. 136, 13319-13325 (2014).

45. Kas, R., Kortlever, R., Yilmaz, H., Koper, M. T. M. \& Mul, G. Manipulating the hydrocarbon selectivity of copper nanoparticles in $\mathrm{CO}_{2}$ electroreduction by process conditions. Chemelectrochem 2, 354-358 (2015).

46. $\mathrm{Li}, \mathrm{Y}$. F. et al. Structure-sensitive $\mathrm{CO}_{2}$ electroreduction to hydrocarbons on ultrathin 5-fold twinned copper nanowires. Nano Lett. 17, 1312-1317 (2017).

47. Loiudice, A. et al. Tailoring copper nanocrystals towards $\mathrm{C}_{2}$ products in electrochemical $\mathrm{CO}_{2}$ reduction. Angew. Chem. Int. Ed. 55, 5789-5792 (2016).

48. Roberts, F. S., Kuhl, K. P. \& Nilsson, A. High selectivity for ethylene from carbon dioxide reduction over copper nanocube electrocatalysts. Angew. Chem. Int. Ed. 54, 5179-5182 (2015)

49. Reske, R., Mistry, H., Behafarid, F., Cuenya, B. R. \& Strasser, P. Particle size effects in the catalytic electroreduction of $\mathrm{CO}_{2}$ on $\mathrm{Cu}$ nanoparticles. J. Am. Chem. Soc. 136, 6978-6986 (2014).

50. Raciti, D., Livi, K. J. \& Wang, C. Highly dense Cu nanowires for lowoverpotential $\mathrm{CO}_{2}$ reduction. Nano Lett. 15, 6829-6835 (2015).

51. Alfonso, D. R., Kauffman, D. \& Matranga, C. Active sites of ligand-protected Au-25 nanoparticle catalysts for $\mathrm{CO}_{2}$ electroreduction to CO. J. Chem. Phys. 144, 184705 (2016).

52. Fang, Y. X. \& Flake, J. C. Electrochemical reduction of $\mathrm{CO}_{2}$ at functionalized Au electrodes. J. Am. Chem. Soc. 139, 3399-3405 (2017).

53. Keller, D. E., Koningsberger, D. C. \& Weckhuysen, B. M. Elucidation of the molecular structure of hydrated vanadium oxide species by X-ray absorption spectroscopy: Correlation between the $\mathrm{V} \ldots \mathrm{V}$ coordination number and distance and the point of zero charge of the support oxide. Phys. Chem. Chem. Phys. 8, 4814-4824 (2006).

54. Li, G. G., Bridges, F. \& Booth, C. H. X-ray-absorption fine-structure standards: A comparison of experiment and theory. Phys. Rev. B 52, 6332-6348 (1995).

55. Rockenberger, J. et al. EXAFS studies on the size dependence of structural and dynamic properties of CdS nanoparticles. J. Phys. Chem. B. 101, 2691-2701 (1997).

56. Jentys, A. Estimation of mean size and shape of small metal particles by EXAFS. Phys. Chem. Chem. Phys. 1, 4059-4063 (1999).

57. Becke, A. D. Density-functional thermochemistry. III. The role of exact exchange. J. Chem. Phys. 98, 5648-5652 (1993).
58. Lee, C. T., Yang, W. T. \& Parr, R. G. Development of the Colle-Salvetti correlation-energy formula into a functional of the electron-density. Phys. Rev. B 37, 785-789 (1988).

59. Frisch, M. et al. Gaussian 09, Revision D. 01 (Gaussian, Inc., Wallingford CT, 2009).

60. Weigend, F. \& Ahlrichs, R. Balanced basis sets of split valence, triple zeta valence and quadruple zeta valence quality for $\mathrm{H}$ to $\mathrm{Rn}$ : Design and assessment of accuracy. Phys. Chem. Chem. Phys. 7, 3297-3305 (2005).

61. Krishnan, R., Binkley, J. S., Seeger, R. \& Pople, J. A. Self-consistent molecularorbital methods. XX. A basis set for correlated wave-functions. J. Chem. Phys. 72, 650-654 (1980)

62. Marenich, A. V., Cramer, C. J. \& Truhlar, D. G. Universal solvation model based on solute electron density and on a continuum model of the solvent defined by the bulk dielectric constant and atomic surface tensions. J. Phys. Chem. B. 113, 6378-6396 (2009).

63. Bard, A. J., Parsons, R. \& Jordan, J. Standard Potentials in Aqueous Solution (CRC Press, New York, 1985).

64. Jiang, Q., Li, J. C. \& Chi, B. Q. Size-dependent cohesive energy of nanocrystals. Chem. Phys. Lett. 366, 551-554 (2002).

65. Greenwood, N. N. \& Earnshaw, A. Chemistry of the Elements 2nd edn (Butterworth-Heinemann, Oxford, 1997).

66. Kittel, C. Introduction to Solid State Physics 8th edn (John Wiley \& Sons, New York, 2004).

\section{Acknowledgements}

The work is supported by the National Science Foundation (Grant CHE-1651717), the Doctoral New Investigator grant from the ACS Petroleum Research Fund, the Global Innovation Initiative from Institute of International Education, and the Callahan Faculty Scholar Endowment Fund from Oregon State University. The synthetic work was supported by the U.S. Department of Energy, Chemical Sciences, Geosciences, and Biosciences Division, Office of Basic Energy Sciences, Office of Science (Grant DEFG0207ER15909). Additional support was provided by a generous donation from the TomKat Foundation. V.S.B. acknowledges support from the Air Force Office of Scientific Research grant FA9550-13-1-0020 and supercomputing time from the NERSC. Y.L. acknowledges financial support from Shenzhen Fundamental Research Funding (JCYJ20160608140827794) and Peacock Plan (KQTD20140630160825828). XAS measurements were done at 5-BM-D of DND-CAT at Advanced Photon Source (APS) of Argonne National Laboratory (ANL). DND-CAT is supported through E. I. duPont de Nemours \& Co., Northwestern University, and The Dow Chemical Company. The use of APS of ANL is supported by DOE under Contract Number DE-AC02-06CH11357.

\section{Author contributions}

Z.W., Y.L., Z.F., and H.W. conceived the project. J.J. and X.-F.W. synthesized the materials. Z.W. and S.H. carried out the electrochemical measurements and material characterization. Z.W., M.W., Q.M., and Z.F. carried out the in-situ and operando XAS measurements. Y.W. and K.Y. performed cluster size analysis and DFT calculations. M.W. and Z.F. analyzed the XAS data. Z.W., Y.W., Z.F., and H. W. wrote the manuscript. G.W.B, V.S.B, Y.L., Z.F., and H.W. supervised the project. All authors discussed the results and commented on the manuscript.

\section{Additional information}

Supplementary Information accompanies this paper at https://doi.org/10.1038/s41467 018-02819-7.

Competing interests: The authors declare no competing financial interests.

Reprints and permission information is available online at http://npg.nature.com/ reprintsandpermissions/

Publisher's note: Springer Nature remains neutral with regard to jurisdictional claims in published maps and institutional affiliations.

Open Access This article is licensed under a Creative Common Attribution 4.0 International License, which permits use, sharing, adaptation, distribution and reproduction in any medium or format, as long as you give appropriate credit to the original author(s) and the source, provide a link to the Creative Commons license, and indicate if changes were made. The images or other third party material in this article are included in the article's Creative Commons license, unless indicated otherwise in a credit line to the material. If material is not included in the article's Creative Commons license and your intended use is not permitted by statutory regulation or exceeds the permitted use, you will need to obtain permission directly from the copyright holder. To view a copy of this license, visit http://creativecommons.org/ licenses/by/4.0/.

(C) The Author(s) 2018 